\title{
Structural Cycles and Industrial Policy Alignment: The private-public nexus in the Emilian Packaging Valley
}

\author{
Antonio Andreoni*, Federico Frattini** and Giorgio Prodi ${ }^{* *}$ \\ *Department of Economics, SOAS University of London \\ **Department of Economics and Management, University of Ferrara
}

\begin{abstract}
The article investigates changes in the interaction between business organisations, local governments and public technology intermediaries resulting from business organisations' shifts towards higher value product segment opportunities. Specifically, we analyse how local governments can (or not) align their industrial policies to the industrial transformations - both technological and organisational underpinning firms' value creation-capture dynamics. The concept of structural cycle is introduced here to study the two interdependent processes of 'technology transition' and 'organisational reconfiguration' characterising those firms shifting towards higher value product segments. This private-public nexus is investigated in the Emilian Packaging Valley context. The mixed-method study focuses on the case of IMA Spa, its shifts from the food to the pharmaceutical value product segment of the packaging machine industry and its changing relationships with regional public policies and institutions. A number of industrial policy implications for sustainable value creation dynamics in local production systems are finally derived.
\end{abstract}

Keywords: structural cycle; industrial policy; policy alignment; packaging machine industry; Emilia-Romagna

JEL Classification: O25; O33; L23. 
This is a pre-copyedited, author-produced PDF of an article accepted for publication in Cambridge Journal of Economics following peer review. The version of record is available online at:

http://cje.oxfordjournals.org/content/early/2016/10/07/cje.bew048.abstract

Accepted Version downloaded from SOAS Research Online: http://eprints.soas.ac.uk/23184/

\section{Introduction}

Modern manufacturing systems consist of complex and dynamic interdependencies spanning across various industries and sectors. These interdependences unfold in a wide range of technological, organisational and institutional dimensions and involve different types of system actors. These include business organisations, both competing and cooperating in multi-tiered and 'glo-cal' production systems, but also various types of public and public-private technology intermediaries and multi-level public policy actors. Within these manufacturing systems, structural economic dynamics are mainly triggered by changes in the technology platforms underpinning industrial sectors and changes in the firms' resource-capabilities. In turn, the adoption of new technologies at full industrial scale often requires organisational reconfigurations involving both the Marshallian 'internal' and 'external' firm.

Industrial sectors are based on different technology platforms integrating various sets and types of technologies whose configurations and interfaces change over time in response to technology push and market pull dynamics (Dosi, 1982; Tassey, 2007). Some of these technology platforms underpin production processes of closelyrelated industrial sectors as well as different value product segments within the same industrial sector. Technologies are thus linked by a set of dynamic interlocking relationships spanning across different sectors and different value product segments. The emergence of these dynamic interdependencies as well as the technology transition from one type of technology platform to another tends to follow cyclical patterns. Often these technology transitions open new value product segments opportunities for business organisations. The existence of technology cycles is particularly evident in relation to technology transitions underpinning firms' shifts from mature declining product segments to new, rising value product segments within the same industrial sector.

The paper investigates how the interaction between business organisations, local governments and various types of local technology intermediaries changes in particular conjunctures, that is, when business organisations shift towards higher value product segments within the same industry. Specifically, the paper provides a theoretical and empirical analysis of the ways in which local governments may (or not) align their industrial policies and public technology intermediaries to the industrial transformations - both technological and organisational - affecting business organisations and the local production system in which they are embedded.

The concept of structural cycle is introduced here to describe two interdependent processes of 'technology transition' and 'organisational reconfiguration'. These two processes characterise those business organisations moving from mature or 
This is a pre-copyedited, author-produced PDF of an article accepted for publication in Cambridge Journal of Economics following peer review. The version of record is available online at:

http://cje.oxfordjournals.org/content/early/2016/10/07/cje.bew048.abstract

Accepted Version downloaded from SOAS Research Online: http://eprints.soas.ac.uk/23184/

declining value product segments to new, higher value product segments within the same industrial sector. Within local production systems, the challenges associated with technology transitions and organisational reconfigurations are major concerns for local governments. The reason is that sustainable value creation dynamics in local production systems depend critically on the capacity of its business organisations - especially system integrator firms - to capture value along and across technology cycles. In other words sustainability depends on the ability of these firms and other organisations to shift from mature or declining product segments to new higher value product segment opportunities.

The effectiveness of local governments' support largely depends on their industrial policies (and, their public technology intermediaries - PTIs) being aligned to these structural cycles. The existing industrial policy literature has failed to take into account issues of the technology cycle and organisation reconfigurations that are taking place in the moment policy-makers are setting out key plans. This is particularly important given that industrial policy is orientated to the future so policy-makers should be aware not only of these transformations taking place at the moment of policy creation but also the cycle of transformations taking place across all moments of long-term policy implementation.

The analytical approach of the paper builds on a theoretical synthesis combining structural dynamics theories of the Cambridge school, resource-capability theories of the firm and evolutionary approaches to technological change, including life cycles theories. Structural dynamics approaches focus on the sectoral re-composition and business cycles of the economic system. They also identify those macroeconomics conditions that must be satisfied to reach certain policy objectives (e.g. full employment). Given their meso-macro perspective, however, micro-learning dynamics, technological change and firm-level organisational reconfigurations remain largely unexplored. In contrast, the resource-capability theories of the firm in combination with evolutionary analyses of technological change focus exactly on those micro technological and organisational processes and dynamics constituting what we have called here 'structural cycles'. These structural cycles, in turn, result in changes to the technology coefficients of the overall production matrix of the economic system, as highlighted in structural economic dynamics theories.

While a complete theoretical synthesis is beyond the scope of this paper, section 2 sketches a number of theoretical interfaces and complementarities between these heterodox theories. Building on this synthesis, section 3 introduces the concept of structural cycle as a new heuristic for conducting micro-structural analyses of the private-public nexus (and its changes) in local production systems. It is argued that local government's industrial policies and technology intermediaries can support (and, sometimes, steer) shifts towards higher value product segments by aligning public policies to structural cycles. These policy interventions must be selective, 
This is a pre-copyedited, author-produced PDF of an article accepted for publication in Cambridge Journal of Economics following peer review. The version of record is available online at:

http://cje.oxfordjournals.org/content/early/2016/10/07/cje.bew048.abstract

Accepted Version downloaded from SOAS Research Online: http://eprints.soas.ac.uk/23184/

operate at different levels of the industrial system and provide differentiated support to the actors in the local production system.

The second part of the paper (section 4) deploys the new structural-cycles policyalignment framework in the context of the Emilian Packaging Valley (EPV), the highest concentration of packaging machine producers in the world. The empirical analysis builds on a multi-methods and multi-disciplinary approach combining patent data analysis, engineering-informed analysis of packaging machinery technologies, in-depth firm-level qualitative data collection and regional-level industrial policy mapping.

The firm-level analysis starts from the system-integrator IMA Spa (IMA hereafter), one of the world leaders in the packaging machine industry, and the Regional Government of Emilia-Romagna in Italy, including its various PTIs. The case study analysis builds on the structural-cycle policy-alignment theoretical framework and develops an innovative way to analyse changes in the private-public nexus. Building on both the theoretical and empirical contributions of the paper, the last section concludes by sketching a number of implications for industrial policy. It also emphasises the policy relevance of developing a structural-resource-capability theoretical synthesis. This heterodox synthesis would enhance local industrial policy effectiveness and their responsiveness to industrial transformations.

\section{Industrial transformations: Towards a structural-resource-capability synthesis}

Industrial transformation is a complex process as it involves both the continuous sectoral re-composition of the economic system and changes in the quality and composition of demand (Kuznets, 1971; Kaldor, 1972; Landesmann and Scazzieri, 1990; Pasinetti, 2007). In particular, structural change entails both a process of intersectoral transition (i.e. moving across sectors, from low to medium and high productivity sectors) and of intra-sectoral deepening (i.e. moving within sectors, from low to high value added activities and product segments). Alongside these sectoral re-compositions, the increasing division of labour among business organisations depends on the increasing 'extent of the market'. In turn, the extent of the market depends on the deepening of the production matrix (Young, 1928).

Building on the seminal contributions of economists such as Joan Robinson (1956 and 1977) and Nicholas Kaldor (1967 and 1972), Luigi Pasinetti and Richard Goodwin developed multi-sectoral models for the analysis of structural dynamics. Despite the different criteria adopted in the identification of productive sectors (according to their dynamic features in the case of Goodwin and to their final outputs in the case of Pasinetti), structural economic dynamics theories share the 
This is a pre-copyedited, author-produced PDF of an article accepted for publication in Cambridge Journal of Economics following peer review. The version of record is available online at:

http://cje.oxfordjournals.org/content/early/2016/10/07/cje.bew048.abstract

Accepted Version downloaded from SOAS Research Online: http://eprints.soas.ac.uk/23184/

same theoretical apparatus. First, they frame economic growth as a sector-specific process (not sector-neutral or activity-neutral as in the more traditional neoclassical model such as Solow's). This means that both productivity (learning in production) and demand (learning in consumption) grow at different rates from sector to sector. Second, as stressed by Pasinetti (2012:553), "[t]he vision behind structural dynamics originates from the consideration of a permanently evolving economic system". Relative economic magnitudes evolve constantly through time and the ongoing disproportional dynamics shape a certain specific structure of the economic system at each point in time. Third, structural economic dynamics unfold at different levels of aggregation according to a specific 'hierarchy of change' determined by both the elements of the systems and their interdependences (Simon, 1962; Landesmann and Scazzieri, 1990; Andreoni and Scazzieri 2013).

In multi-sectoral models, technological change is recognised as one of the main triggers of structural economic dynamics and the unfolding interdependencies across sectors. The seminal contribution by Albert Aftalion (1927) theorised a link between the specific time-requirements for the production of new industrial equipment and the cyclical fluctuations characterising economic systems. In Nicholas Kaldor's assessment of economic growth, production technologies are the main triggers of productivity increases within manufacturing industries, but also agriculture (Kaldor, 1966 and 1985). Goodwin stressed the existence of technology interdependencies emphasising how "an important innovation in energy, or transport, or automated control, will gradually lead to alteration of least-cost processes in many other sectors and thus will initiate technological change over a long period. This will persist over time, not only because any such improvement undergoes prolonged small improvements, but also because it usually needs extensive adaptation to a variety of uses" (Goodwin, 1987, p. 147; italics added).

Although these theories provide powerful lenses to frame multi-sectoral interdependencies (within different time horizons) and assign a central role to technological change, the latter is mainly treated as a theoretical exogenous construct to explain the sources of structural dynamism. This implies a number of limitations. First the 'real' technological dynamics, their development and cyclical deployment in different sectors cannot be easily explained. Similarly, the ways in which technological change requires (and, in some cases produces) organisational reconfiguration in firms (and the production systems in which they are embedded) is neglected. Finally, while shifts from low-tech sectors to more advanced sectors have been widely researched, industrial transformation consisting of transitions from mature product segments to new higher value product segments within the same industrial sector remain largely ignored.

These limitations call for an investigation of potential theoretical interfaces linking structural economic theories and micro-structural theories of the firm, industrial 
This is a pre-copyedited, author-produced PDF of an article accepted for publication in Cambridge Journal of Economics following peer review. The version of record is available online at:

http://cje.oxfordjournals.org/content/early/2016/10/07/cje.bew048.abstract

Accepted Version downloaded from SOAS Research Online: http://eprints.soas.ac.uk/23184/

organisation and technological change. Two of these theoretical interfaces are particularly important for understanding the ways in which the relationships between business organisations and public policies change over time. One relates to value creation dynamics and technological change within business organisations, triggering structural dynamics and changes in technology coefficients of the overall production matrix. The other connects sectoral re-compositions (including changes in the value of product segments and related technological changes) and organisational reconfigurations within business organisations (and the production systems in which they are embedded).

Starting with the first theoretical interface, in the resource-capability theory of the firm, value creation dynamics (underpinning industrial transformations) are mainly explained as learning processes whereby business organisations accumulate (but also continuously develop) their internal pool of resources in response to new production opportunities (Penrose, 1959; Teece, 2007). In contrast to Coase's transaction cost theory of the firm (Coase, 1937), in the resource-capability framework creating a firm may in fact denote the highest value option for the creation and development of internal resources-capabilities (Penrose, 1959; Richardson, 1972; Demsetz, 1988; Best, 1990; Lazonick, 2010).

Penrose's (1959:149) definition of the firm as "a pool of resources the utilisation of which is organized in an administrative framework" introduces two related pathbreaking propositions for understanding how structural change and disproportional economic dynamics originate within business organisations. First, the firm is a collection of physical and human resources that can be deployed in a variety of ways to provide a variety of productive services. In other words, "the services yielded by resources are a function of the way in which they are used - exactly the same resource when used for different purposes or in different ways and in combination with different types or amounts of other resources provides a different service or set of services" (Penrose 1959:25). Therefore, heterogeneity within sectors and across firms, results from business organisations' almost unique pool of internal resources and the ways in which firms combine and deploy them in different value product segments. These combinations and re-combinations allow firms to shift to higher value product segments or even move to similar or closely complementary sectors (Andreoni, 2014). The second related proposition is that the growth of the firm occurs through the recognition and exploitation of productive opportunities, specifically of "all of the productive possibilities that its entrepreneurs see and can take advantage of" (Penrose, 1959:31).

As for the second theoretical interface, learning dynamics do not simply concern the 'internal' organisation of the firm, they also relate to its 'external' organisation and, ultimately, to the overall industry organisation and its sector-specific structure. George B. Richardson's work (1960 and 1972) is among the first to focus on how 
This is a pre-copyedited, author-produced PDF of an article accepted for publication in Cambridge Journal of Economics following peer review. The version of record is available online at:

http://cje.oxfordjournals.org/content/early/2016/10/07/cje.bew048.abstract

Accepted Version downloaded from SOAS Research Online: http://eprints.soas.ac.uk/23184/

industry organisation develops as a result of both competition dynamics and interfirm cooperation. The drivers of these 'co-opetitive' dynamics, in particular the reasons why certain business organisations choose their 'dancing partners', are explained in relation to firms' internal capabilities.

Richardson (1972:888) describes industries and their firms as entities in which a large number of activities are carried out through the adoption of an appropriate cluster of capabilities "or, in other words, with appropriate knowledge, experience, and skills." Capabilities are built and accumulated via a continuous process of internal resource development but also as a result of capabilities-driven organisational reconfigurations involving the 'internal' as well as 'external' firm (Wilkinson, 1983; Best, 1999; Pitelis, 2002; Pitelis and Teece, 2009; Lazonick, 2010; Pitelis, 2012; Andreoni, 2014). Richardson (1972) emphasised how business organisations tend to specialise in the execution of a certain set of interrelated production tasks (i.e. similar activities) that only require a limited set of capabilities. At the same time, in expanding or upgrading the value of their product segments, firms need to acquire closely complementary but dissimilar capabilities. Business organisations have two options: either gaining control of the capabilities of other business organisations (e.g. through acquisitions and inter-firm cooperation) or obtaining access to them (e.g. through the institution of the market).

Therefore, as Marshall (1920) noted, evolution through the division of labour tends to favour both greater specialisation (increasing capabilities) and closer integration (an increasing number of organisational configurations to coordinate capabilities and activities). Thus, capabilities dynamics are at work at the very basis of the organisation of industry, especially of local production systems organisational structure and change. They also affect sectoral trajectories and their unfolding interdependencies over time. In fact, similarities and complementarities in production tasks do not simply shape the organisation of industry, they also generate technological interdependencies across sectors and different product-value segments within the same sector (Rosenberg, 1976 and 1994; Loasby, 1999; Andreoni, 2014).

Evolutionary economics have focused on these different trajectories of technological change triggered by co-evolving demand-pull and technology-push dynamics within a 'technology paradigm' model (Schumpeter, 1911; Nelson and Winter, 1982; Dosi, 1982). Specifically, by investigating changes in 'organisational routines' by heterogeneous and rationally-bounded individuals and organisations, evolutionary approaches have provided a behavioural-foundation of firm-level processes of techno-organisational change (Simon, 1983 and 1991; Nelson and Winter, 2002; Dosi et al. 2000). These approaches are consistent with resource-capability theories of the firm and their emphasis on firms' micro-learning and organisational dynamics. 
This is a pre-copyedited, author-produced PDF of an article accepted for publication in Cambridge Journal of Economics following peer review. The version of record is available online at:

http://cje.oxfordjournals.org/content/early/2016/10/07/cje.bew048.abstract

Accepted Version downloaded from SOAS Research Online: http://eprints.soas.ac.uk/23184/

\section{Structural cycles: technology transition, organisational reconfiguration and policy alignment}

The structural-resource-capability synthesis introduced in section 2 allows the formulation of a number of hypotheses about how the relationship between business organisations and public policy changes both over time and in particular conjunctures (i.e. when firms capture the opportunity of shifting toward higher value product segments). This synthesis provides the analytical categories for reconstructing the specific technological and organisational dynamics within business organisations and their bi-directional causational link with meso-level structural dynamics. Moreover, a structural-resource-capability synthesis also offers a framework for stylising the different potential models that governments and PTIs can follow to respond to (or steer) these industrial transformations. Specifically, this paper focuses on the public policies that local governments can implement in the critical conjuncture when business organisations shift towards higher value product segments.

At the micro level, the development of new technologies or their deployment in new higher value product segments can open new opportunities for value capture with new products. These will be ultimately shaped by technology-push and market-pull dynamics and will require organisational reconfigurations at the level of the firm and within the local production system. These micro-level technological transitions and organisational reconfigurations tend to follow time specific patterns of change, also of a cyclical nature, and arise from location specific production systems. The reason is that changes and reconfigurations unfold within specific technological and sectoral structures, often imposing hierarchical constraints and a specific 'rhythm' to change (Simon, 1962). In turn, these micro technological and organisational dynamics may affect sectoral re-compositions and their speed of change. They can also establish new technological relationships between industrial sectors and their underpinning technology platforms (Tassey, 2007; Andreoni, 2014).

Building on these stylisations, one of the main analytical challenges is to disentangle the way in which technological and organisations dynamics unfold according to specific time patterns and in specific organisational settings. On this basis, it becomes possible to assess the changing relationships between business organisation and public policies. From the meso-macro perspective, the complementary challenge consists of understanding how sectoral dynamics, their speed and magnitude, result 
This is a pre-copyedited, author-produced PDF of an article accepted for publication in Cambridge Journal of Economics following peer review. The version of record is available online at:

http://cje.oxfordjournals.org/content/early/2016/10/07/cje.bew048.abstract

Accepted Version downloaded from SOAS Research Online: http://eprints.soas.ac.uk/23184/

from time specific patterns of technological and organisational change in specific production systems.

In the existing literature, some (limited) advances have been made towards meeting these challenges already. For example, alongside developments in evolutionary economics, and partially building on them, the 'product life-cycle' and 'industry lifecycle' theories have investigated time specific patterns of technological change for specific products or specific industrial sectors respectively (Segerstrom et al., 1990; Klepper, 1997). Product life-cycle theories extrapolate time specific patterns of change by focusing on the relationships between product innovation, demand growth and firms' entry patterns. Additionally, industry life-cycle models á la Klepper tend to include the possibility of increasing returns and continuous opportunities for product and process innovation in the industry. Here, technological change is seen as co-evolving with the industry market structure and changes in the vertical structures of firms over time.

These theoretical perspectives are, however, limited in three main respects. First, despite their partial emphasis on specific firms' behaviour and market dynamics at later stages of the cycle, mature industrial systems are mainly investigated from the point of view of industry concentration and firm selection, increasing oligopolistic price-competition and technological lock-in. Less emphasis is given to the ways in which firms undergo processes of technology transition triggered by changes in the technology platforms underpinning the industry and the discovery of new value product segments (within the same industry). In other words, the resource-capability dynamics underpinning technology transitions are not captured.

Second, despite the emphasis on changes in market structures, the way in which technology transitions trigger (and are made possible by) organisational reconfiguration in specific settings - i.e. local production systems - is again underexplored. The reason is that life-cycle theories mainly understand product and industry cycles from the point of view of large firms without enough consideration of changes in local production systems along the cycle. This limitation has been recently highlighted by those contributions focusing on cluster life-cycles (Menzel and Fornahl, 2009), the life-cycle of industries from the point of view of agglomeration externalities (Neffke et al., 2011) and, finally, the value co-creation dynamics in clusters and entrepreneurial ecosystems (Pitelis, 2012).

Third, despite the emphasis on industry life-cycles, the ways in which technology transition and organisational reconfigurations in local production systems trigger processes of structural change within and across sectors is not even considered. In other words, no link is established between time specific patterns of change within industries and the overall structural dynamics reshaping the economic system. 
This is a pre-copyedited, author-produced PDF of an article accepted for publication in Cambridge Journal of Economics following peer review. The version of record is available online at:

http://cje.oxfordjournals.org/content/early/2016/10/07/cje.bew048.abstract

Accepted Version downloaded from SOAS Research Online: http://eprints.soas.ac.uk/23184/

The concept of structural cycle is introduced here as a first theoretical attempt to address these limitations and better capture the two fundamental processes of technology transition and organisational reconfiguration characterising business organisations shifting towards higher value product segments. Structural cycles are defined as transformational phases of technology transition and organisational reconfiguration that business organisations experience when they shift towards higher value product segments opportunities.

Technology transitions in mature industrial systems entail both disruptive changes in the main technology platform underpinning a certain industry and the emergence of new higher value product segments within the same industry. These technology transitions are sector specific and follow specific time patterns, sometimes of a cyclical nature. Technology transitions can induce product segment value diversification and drive improvements in mature product segments. This is because new platform technologies may open up new possibilities in the industry and expand the functionalities of the more traditional product-systems (Hobday, 2000).

Technology transitions and organisational reconfiguration are strongly intertwined. A new technology platform makes investment in resource-capability building necessary. As capability theories of the firm highlight, business organisations respond to this challenge by either adopting vertical integration strategies or establishing strategic horizontal partnerships. These partnerships often involve various (more or less direct) collaborations with companies within the same local production system. Within these production systems, however, technology transitions tend to have disproportional effects on different business organisations. Only a few companies will be able to operate competitively within the new industry technology platform and capture the opportunities for new higher value product segments in the industry. The structural cycle is a product of these cumulative dynamics resulting from technology transition and organisational reconfigurations (Fig 1). 
This is a pre-copyedited, author-produced PDF of an article accepted for publication in Cambridge Journal of Economics following peer review. The version of record is available online at:

http://cje.oxfordjournals.org/content/early/2016/10/07/cje.bew048.abstract

Accepted Version downloaded from SOAS Research Online: http://eprints.soas.ac.uk/23184/

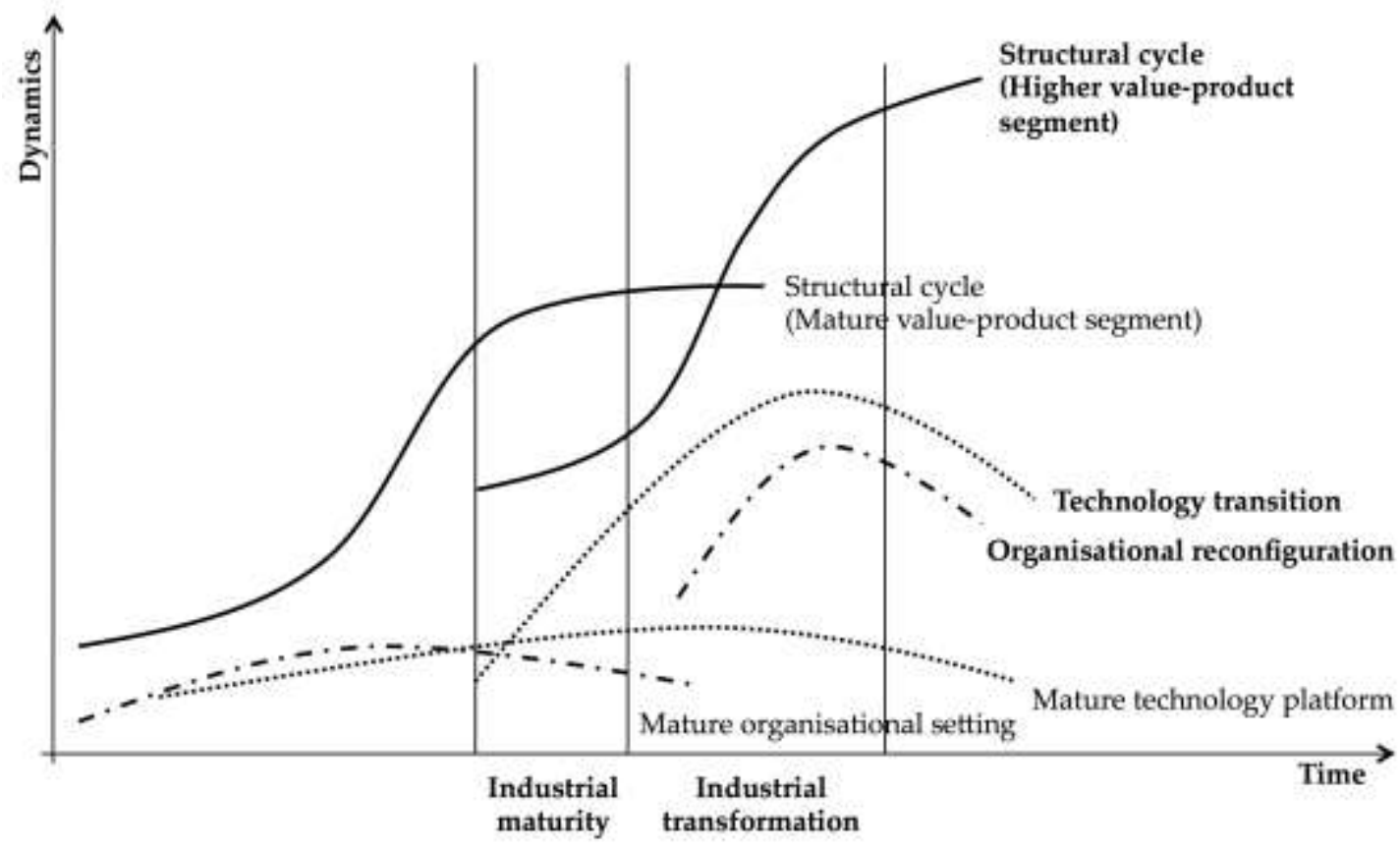

Fig. 1. Stylisation of structural cycles. Source: Authors.

The structural cycles we have described so far entail the transition of business organisations from one product segment to a new higher value one within the same industry. However, this transition within the same industrial sector may induce potential cross-sectoral dynamics as well. This means that the technology transitions and organisational reconfigurations experienced by some firms in mature industrial systems may also prepare the same firms to diversify into closely related industries. The ideas of knowledge and industry relatedness (Breschi et al., 2003; Neffke, et al. 2011) and intersectoral learning (Andreoni, 2014) offer insights about how the structural cycles described here are linked to business diversification and structural economic dynamics across sectors.

The concept of structural cycle is not simply a heuristic for disentangling and better interpreting the industrial transformation processes. It also facilitates the analysis of how to best intervene in these transformation processes, helping to ensure public policies aimed at supporting industrial transformation are aligned with the time specific patterns of technological and organisational change in specific production systems. Without such structural cycle - industrial policy alignment the effectiveness of policy interventions is limited. Industrial policy effectiveness depends on governments' capacity to address structural constraints and opportunities at different levels of the industrial system and in a selective and timely way (Chang, 1994; Mahoney et al., 2009; O'Sullivan, et al. 2013; Mazzucato, 2013; Andreoni, 2016; Chang and Andreoni, 2016). 
This is a pre-copyedited, author-produced PDF of an article accepted for publication in Cambridge Journal of Economics following peer review. The version of record is available online at:

http://cje.oxfordjournals.org/content/early/2016/10/07/cje.bew048.abstract

Accepted Version downloaded from SOAS Research Online: http://eprints.soas.ac.uk/23184/

The alignment of industrial policies to structural cycles requires governments taking an entrepreneurial role in critical phases of technology transition and organisational reconfiguration. Engaging business organisations with an entrepreneurial approach requires the design of selective packages of policy interventions and the development of various types of PTIs such as applied technology and training centres, university-based technology development centres and specialised publicprivate industrial labs (Andreoni, 2016).

More specifically, entrepreneurial governments can operate along three main axes.

First, local governments can support business organisations in the development of system interfaces and infrastructure, as well as support them in the discovery of new product segments and market opportunities. These activities may involve various types of public-private partnerships mediated by co-founded PTIs, incentive schemes for strategic public-private partnerships and local industry associations. Given their technology platform focus, these PTIs and public policies will tend to have an indirect cascade effect on the entire local multi-tiered production system in which these system-integrator business organisations operate.

Second, governments can provide direct support to dynamic first- and second- tier suppliers in the adoption of (and adaptation to) new technology platforms. These include new production technologies, software-hardware integration technologies, advanced instrumentation and standardisation and the development of specific technology platform components.

The third and final axis of public policy intervention targets those companies which are not directly leading the structural cycles in mature industrial systems but are indirectly involved through sub-contracting and supplier relationships in local production systems (mainly SMEs and second-tier suppliers). While these companies may benefit from the existence of various PTIs, their readiness to change also depends on the availability of well-trained technicians and access to advanced instrumentations and other enabling infra-technologies (Tassey, 2007; Andreoni, 2016).

To recap, the first industrial policy axis involves a direct interaction with leading companies, that is, system integrators in local production systems who have direct access to the final market. These are also the companies that generally lead the initial stages of technology transition and orchestrate local networks of producers. The second and third axes of intervention target the overall readiness to change of the local production system via diffused technical capabilities building and provision of enabling infra-technologies. The following section will provide an empirical analysis of structural cycles in the context of the packaging industry and an in-depth investigation of the private-public nexus in the EPV. 
This is a pre-copyedited, author-produced PDF of an article accepted for publication in Cambridge Journal of Economics following peer review. The version of record is available online at:

http://cje.oxfordjournals.org/content/early/2016/10/07/cje.bew048.abstract

Accepted Version downloaded from SOAS Research Online: http://eprints.soas.ac.uk/23184/

\section{The public-private nexus in the Emilian Packaging Valley (EPV): the case of IMA}

The world packaging-machine industry accounts for a total turnover of over 33 billion US\$ and is composed of four main product segments: food, beverage, personal care, and pharmaceutical packaging. Over the past 15 years, the industry has grown at a cumulative rate of $15 \%$, with the pharmaceutical packaging value product segment (Pharma hereafter) growing at over 20\%. Together with BadenWürttemberg and Hessen in Germany, Emilia-Romagna (ER) in Italy is the regional industrial system with the highest concentration of firms producing automatic packaging machines (Fortis and Carminati, 2014) ${ }^{1}$. Although a large number of SMEs operating as subcontractors have historically composed the local production system in the EPV (Brusco, 1982), four global leaders are also located in this area: IMA, GD, SACMI and Marchesini. Among them, IMA has been the most successful in shifting towards the highest value product segment of the packaging industry - i.e. Pharma. Moreover, the regional public institutions in ER, including the government, universities and the PTIs have been traditionally very active supporters of the regional industrial system (Amin, 1999; Bianchi and Labory, 2011). Building on the structural cycles - policy alignment framework, we decided to study the ways in which the interactions between IMA and ER's public institutions and policies have been changing as a result of IMA's shift towards the Pharma segment of the packaging industry.

\subsection{Methods}

This study adopts a mixed-method, multi-staged and multi-disciplinary approach. Technology-cycles and changes in the industry's technology platforms are difficult to capture. Despite a number of limitations, patent data are often used as proxy for technological activities and change (Keller, 2004). Clearly, inventions are not all patented, but the most relevant and valuable inventions are often patented (Griliches, 1990). In order to track the technology-cycles and major transformations in the technology platform underpinning the sector, we first conducted patent analysis at the industry, product segment and company levels as well as at the packaging machine system and sub-system levels.

First, this analysis begins by building on the OECD, REGPAT database (February 2015) which reports patent applications to the European Patent Office (EPO). Focusing on the period from 1980 to 2010 we looked at technologies that are classified in section B65 (conveying; packing; storing; handling thin or filamentary materials) of the International Patent Classification (IPC). Two subsets of 
This is a pre-copyedited, author-produced PDF of an article accepted for publication in Cambridge Journal of Economics following peer review. The version of record is available online at:

http://cje.oxfordjournals.org/content/early/2016/10/07/cje.bew048.abstract

Accepted Version downloaded from SOAS Research Online: http://eprints.soas.ac.uk/23184/

technologies were identified as specific for packaging of the food and tobacco segment (F\&T) and the pharmaceutical products segment (Pharma). In particular, we looked at the additional IPC subclasses mentioned by patent documents grouped at the sectoral level (Schmoch et al., 2003)2. Thus, we obtained a comprehensive group, and two segment subgroups, of packaging technologies. The data extracted are only a subset of all patented inventions in the global packaging industry. However, they present two fundamental advantages for cross-segmental comparisons: (i) they are homogeneous with respect to filing procedures and granting practices and (ii) they represent a sort of positively selected subset of inventions (OECD, 2009).

Second, the patent analysis was triangulated with an engineering-informed scoping study focusing on changes in automation control systems, packaging technologies including insulation, sensors, data tracking, big data and advanced materials. We then focused on the adoption and integration in packaging machines of automatic control systems based on electronics, information and communication (EIC) technologies ${ }^{3}$ to investigate why and how these technologies were necessary to shift towards higher value product segments, specifically Pharma. The technology scenario was then validated with a structured technical questionnaire compiled by technologists in two local leading companies (IMA and Marchesini).

Third, we conducted an in-depth case study focusing on the technology transition and organisational reconfiguration of IMA. IMA is today's world leader in the production of packaging machines and integrated packaging lines for the Pharma segment with a world market share of $16 \%$. Since 1960s IMA has grown dramatically, from being a medium-sized enterprise employing 50 people with revenues around $€ 500$ thousands to becoming a global group with 4.600 employees and $€ 854.6$ million revenues in 2014. The case study included a total of 30 interviews conducted between June 2014 and May 2015. Interviews targeted IMA and a selected number of its key first-tier and second-tier suppliers. Among them, Logimatic Srl and I.E.M.A. Srl are first-tier subcontractors operating in mechanical assembly and electrical components development respectively. Both of them were deeply involved in the most recent phase of IMA's organisational reconfiguration. Data were also triangulated with targeted interviews with one of IMA's main local competitors (Marchesini).

Fourth and finally, regional policy documents were scanned to map changes in the public policy approach and types of support to the packaging industry. The data were validated through interviews with key players, including the Regional government, ASTER and LIAM. The ER regional government has adopted a wide and articulated range of industrial policies since the 1970s. According to Istat data, the ER manufacturing system contributes one quarter of regional GDP and employment. It includes around 39,000 companies spanning across the machine 
This is a pre-copyedited, author-produced PDF of an article accepted for publication in Cambridge Journal of Economics following peer review. The version of record is available online at:

http://cje.oxfordjournals.org/content/early/2016/10/07/cje.bew048.abstract

Accepted Version downloaded from SOAS Research Online: http://eprints.soas.ac.uk/23184/

tools, packaging, medical devices, plastics, agro-tech, food and automotive sectors. While many studies highlighted the entrepreneurial approach of the regional government to industrial policy in specific historical moments (Brusco, 1982; Bianchi and Bellini, 1991; Amin, 1999; Bianchi and Labory, 2011), our analysis attempted to assess the extent to which these industrial policies that are relevant for the packaging industry have been aligned (or dis-aligned) to its main industrial transformations over time.

\subsection{Technology cycles and transitions in the packaging industry}

Looking at the technology scenario for the overall packaging industry (Fig. 2), there is clear evidence of strong technology dynamism reaching two peaks in 1992 and 2004. This was followed by a stabilisation phase and one of decline respectively, partially caused by the financial crisis. Nonetheless, at the product segment level, we observe two very different patterns for the F\&T and Pharma segments of the industry. Technology applications in the F\&T segment remain fundamentally stable over the entire period, with 60 patents applications per year on average. This suggests that the F\&T segment reached a stage of technology maturity starting from the late 1980s.

In contrast the Pharma segment underwent a long and sustained technology expansionary cycle over the entire period, with a strong acceleration starting from 1998, reaching its peak in 2004. On average, the number of patents applications in the Pharma segment went from 116 a year from 1980 to 1997, to 350 a year from 1998 to 2004. Thus, the expansionary technology-cycle in the packaging machine industry was fundamentally driven by the Pharma segment.

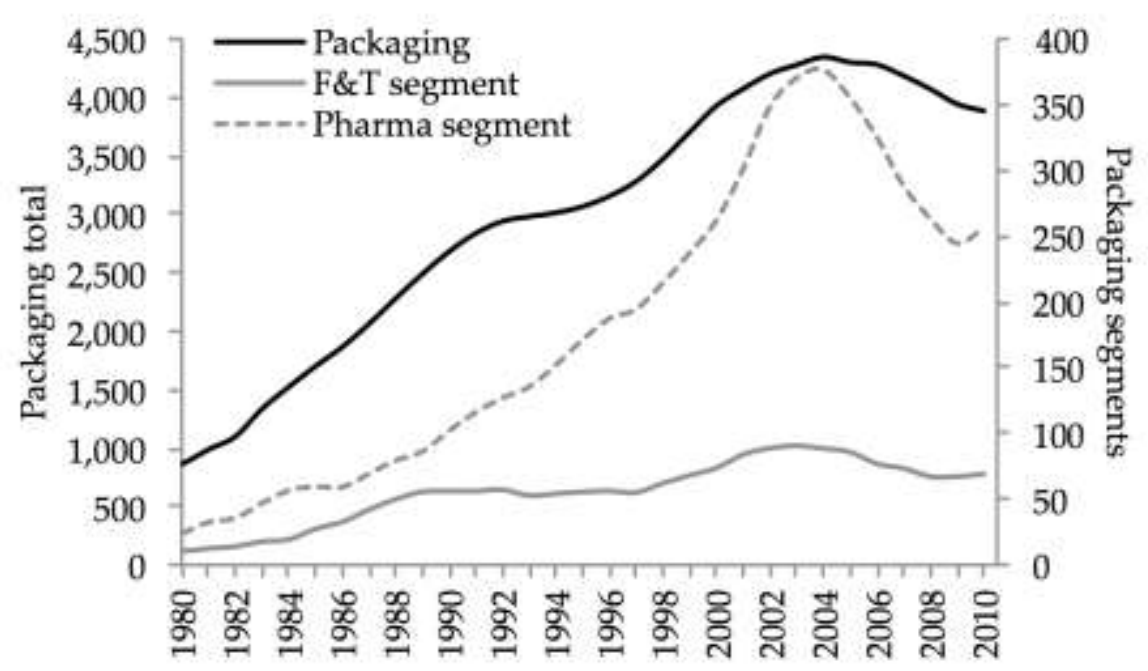


This is a pre-copyedited, author-produced PDF of an article accepted for publication in Cambridge Journal of Economics following peer review. The version of record is available online at:

http://cje.oxfordjournals.org/content/early/2016/10/07/cje.bew048.abstract

Accepted Version downloaded from SOAS Research Online: http://eprints.soas.ac.uk/23184/

Fig. 2. Patent applications to the EPO: Packaging industry, F\&T segment and Pharma segment, 1980-

2010 (5-year average). Source: Authors' arrangement from the OECD, REGPAT database, February 2015.

The Pharma-led expansionary technology-cycle had also spill over effects on the other product-segments within the packaging machine industry. In particular, a number of technologies responding to specific needs of the Pharma segments started affecting other segments of the packaging industry, especially the F\&T segment. From 1998 until 2004, the technological dynamism in the F\&T segment was highly correlated with the strong technological acceleration in the Pharma segment, although patents in the F\&T segment never went above 100 even in this phase given the segment maturity.

This point can be further emphasised by comparing the cyclical components of patent counts at sectoral and value product segment levels. If we extract the standardised cyclical components of the patent applications patterns as plotted in Fig. 2 and we remove the segment specific trends $s^{4}$, we can then identify both the technology cycles for each product segments - F\&T and Pharma - and the technology-cycle of patents applications common to both segments. As shown in Fig. 3, the dramatic technology dynamism in the Pharma segment between 1998 and 2004 was the main driver of the increase in common patents for the two segments and the second technology expansionary cycle in the F\&T segment.

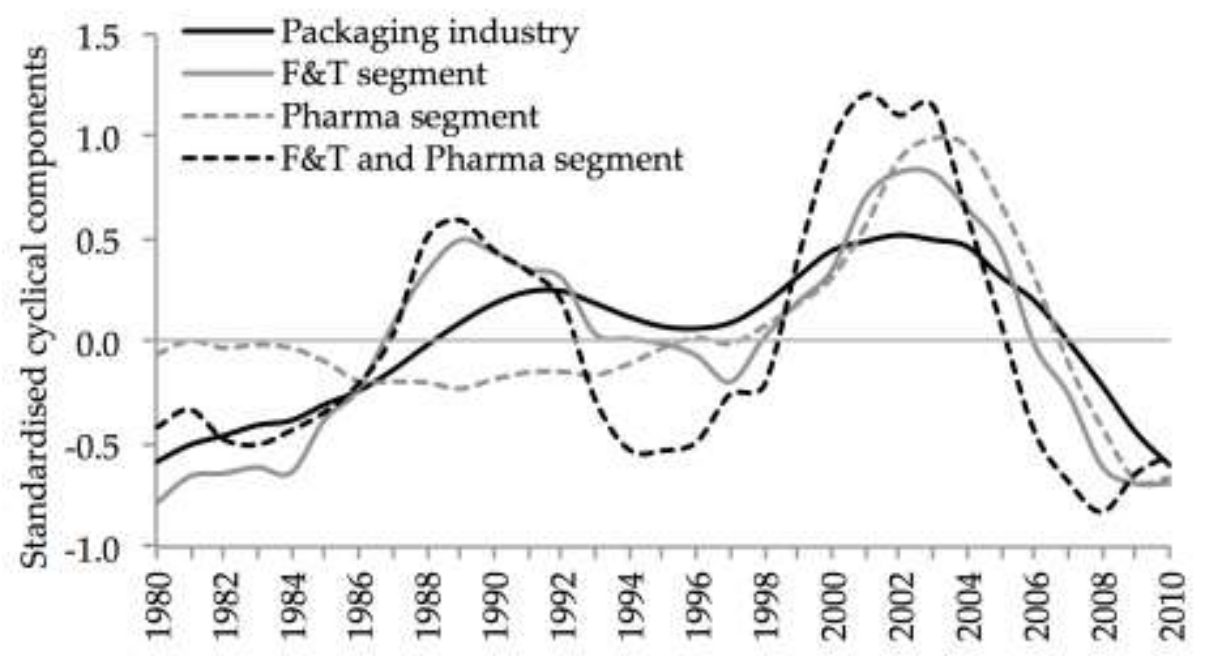

Fig. 3. Standardised cyclical components (calculated over z-scores of patent applications to the EPO): Packaging industry, F\&T segment, Pharma segment and intersection across segments, 1980-2010 (5year average). Source: Authors' arrangement from the OECD, REGPAT database, February 2015. 
During the last 30 years, the most dramatic technological change in the packaging industry has been the transition from mechanics to mechatronics, that is, the adoption and integration in packaging machines of automatic control systems based on electronics, information and communication (EIC) technologies. Patent data reveal how references to EIC technologies underpinning automatic control systems for the packaging industry followed a cyclical trend ${ }^{5}$. Until the mid-1980s control system patents were generic, that is, it is not possible to find significant variations across product segments. However, from 1985 onwards specific patent applications for control system technologies were fundamentally driven by the Pharma segment (Fig. 4). In other words, the Pharma segment was the main driver behind the technology transition in the packaging industry's platform technology and the transition from mechanics to mechatronics.

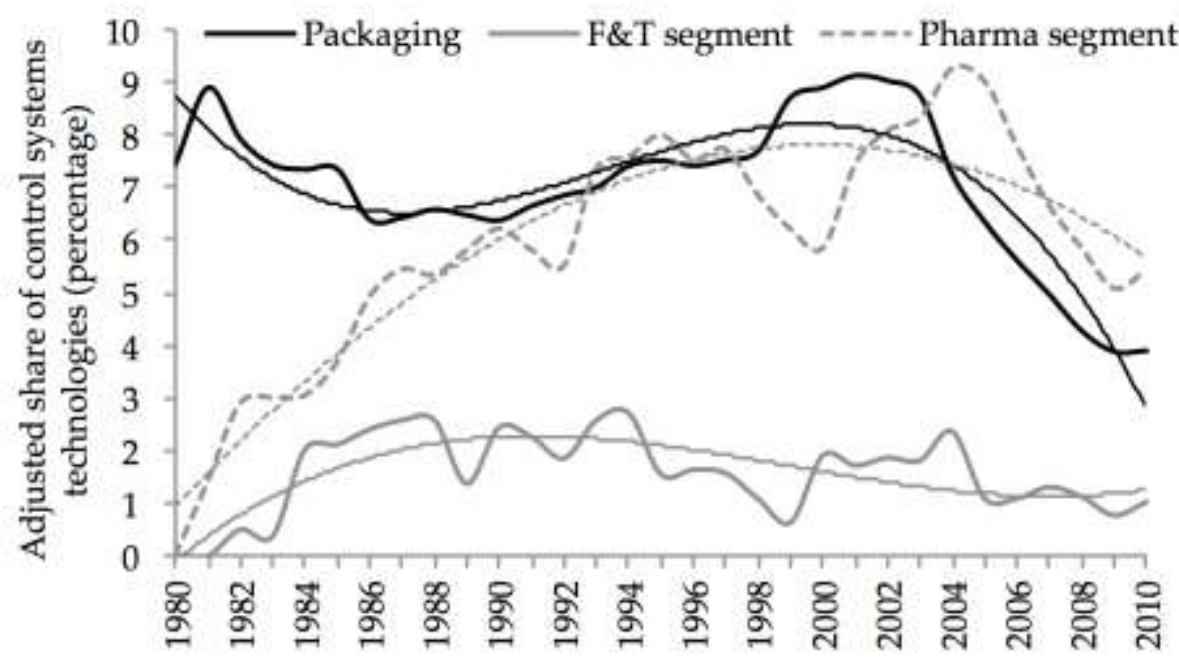

Fig. 4. Adjusted share of control systems technologies (percentage on total excluding F\&T- and Pharma-specific technologies): Packaging industry, F\&T segment and Pharma segment, 1980-2010 (5-year average). Source: Authors' arrangement from the OECD, REGPAT database, February 2015.

This technology transition changed the fundamental technology platform underpinning the packaging machine industry, that is, automated control systems. Specifically, this transition opened higher value product segment opportunities resulting from the increasing operational speed and configuration flexibility of packaging machines, the full traceability of packaged products and the possibility of integrating and standardising entire packaging production lines. These technology properties are particularly important and sometimes vital in the field of 
This is a pre-copyedited, author-produced PDF of an article accepted for publication in Cambridge Journal of Economics following peer review. The version of record is available online at:

http://cje.oxfordjournals.org/content/early/2016/10/07/cje.bew048.abstract

Accepted Version downloaded from SOAS Research Online: http://eprints.soas.ac.uk/23184/

pharmaceuticals and medical disposals because of their extremely high standards of quality, dosage precision, sterilisation and traceability.

With the exception of speed and fast-flexible machine reconfiguration, these properties are relatively less important in the F\&T segment. The fact they are less important does not exclude the emergence of new production opportunities for this segment. In fact, as shown in Fig. 3 and 4, after 1998 the F\&T segment has been partially re-aligning its technology cycle with respect to the automation technologies for control systems. In sum, the evidence from patent analysis supports the idea that shifts towards higher value product segments are triggered by the availability of new technologies and that, in the case of the packaging industries, these technological changes were associated with a new technology platform based on EIC technologies.

\subsection{Technology transition and organizational reconfiguration in the Emilian Packaging Valley: the case of IMA}

The growth of IMA was driven by interlinked technological developments along the packaging industry's technology-cycles. The transition towards higher value product segments also required continuous organisational reconfigurations, especially in relation to its regional production system. While the first phase of IMA's growth mainly relied on the Food segment, the Pharma segment became its main technological, industrial and financial driver from 1995 onwards. In 2008, at the peak of IMA's expansion in this segment, Pharma accounted for almost $85 \%$ of its revenues (Fig. 5).

IMA's technology journey started in 1961 with a packaging machine for water sparkling powder, followed by the production of two packaging machines (the C20 and C25 models) for tea bags and drugs in powder form respectively. The first important technology jump occurred in 1975 with the first blistering machines (the C60 model) for relatively less elementary applications in the Pharma segment. The following twenty years were driven by the global success in the Food segment and the production of increasingly high performance packaging machines for the industry segment. However, during the second part of this period (1975 - 1995) IMA actively engaged the technology transition from mechanics to mechatronics and in the increasing integration of EIC technologies in the packaging industry's platform technology. From a technological perspective, this slow process of resourcecapability development prepared IMA's shift towards higher value product segments. 
This is a pre-copyedited, author-produced PDF of an article accepted for publication in Cambridge Journal of Economics following peer review. The version of record is available online at:

http://cje.oxfordjournals.org/content/early/2016/10/07/cje.bew048.abstract

Accepted Version downloaded from SOAS Research Online: http://eprints.soas.ac.uk/23184/

The technology cycles followed by IMA can be traced by looking at its application patents to the EPO from mid 1990s (Fig. 5). The dramatic increase in technology patents in the Pharma segment between 1995 and 2005 shows IMA's shift from the F\&T to the Pharma segment was driven by a technology transition. In this transition electronics, information and communication technologies (in combination with other advancements in insulation technologies and advanced materials) transformed the packaging machine's technology platform. IMA's technology transition thus mirrors the one followed by the entire packaging industry spurred by the Pharma segment, although IMA anticipated the industry technology cycle by three years (see section $4.2)$.

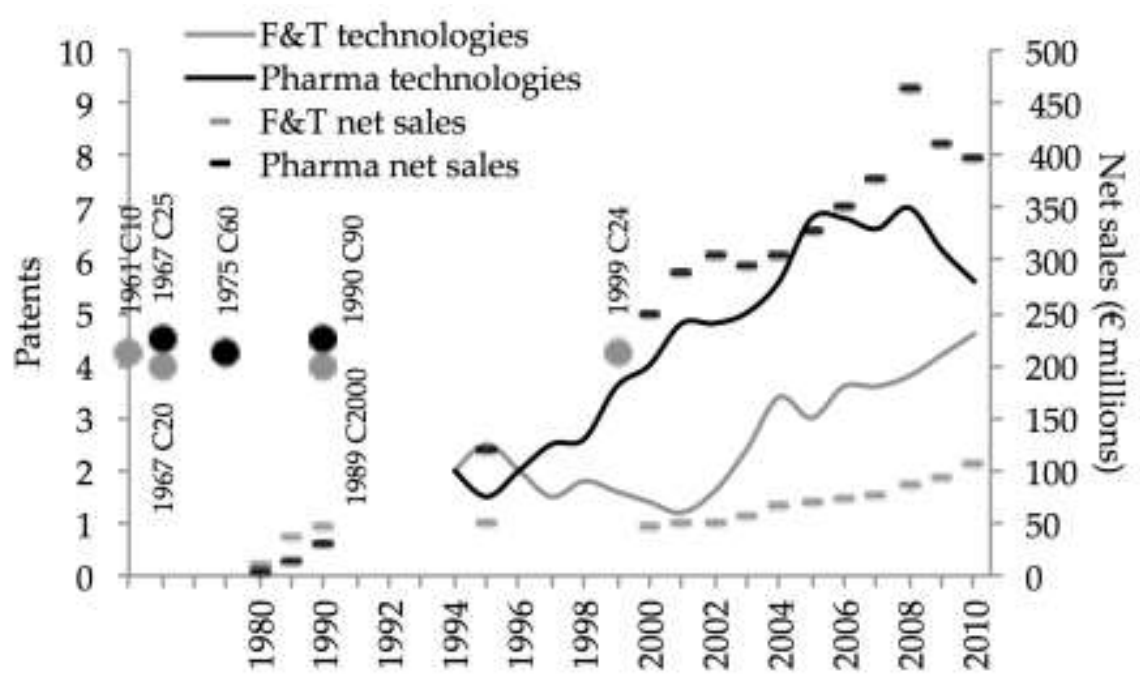

Fig. 5. Innovative machines, technologies (patent applications to the EPO) and net sales by segment: IMA, 1960-2010. Source: Authors' arrangement from IMA interviews, presentations of IMA's company results, IMA website and the European Patent Register (Espacenet).

As already noted for the packaging industry as a whole, within IMA this Pharma-led technological transition had a positive spill-over effect on the more mature product segment Food which registered an upsurge in F\&T patent applications from 2002 onwards. This suggests how, over the past decade, IMA's technology transition towards Pharma has been increasingly transforming IMA resource-capability across segments and potentially preparing a new technology-cycle with new advancements in the F\&T segment such as smart packaging for high-value F\&T products.

IMA's technology transition is strongly intertwined with its organisational reconfiguration and internationalisation which started in the 1980s. However, despite many mergers and acquisitions in the global industry, IMA's major organisational reconfigurations relate to both its internal structure and its strategic relationships with the ER regional production system. 
This is a pre-copyedited, author-produced PDF of an article accepted for publication in Cambridge Journal of Economics following peer review. The version of record is available online at:

http://cje.oxfordjournals.org/content/early/2016/10/07/cje.bew048.abstract

Accepted Version downloaded from SOAS Research Online: http://eprints.soas.ac.uk/23184/

IMA went through two main internationalisation phases. Between 1982 and 1988, IMA started its commercial expansion into the US and Europe (UK, France, Germany and Austria as a doorway to the Eastern European bloc countries). During the following two decades, the commercial expansion continued in Portugal, Spain and Thailand coupled with industrial collaborations in Japan and China and acquisitions in Germany. Today the IMA group is present in 80 countries, although almost $50 \%$ of its employees are still in Emilia-Romagna.

IMA's internationalisation reflects the strong concentration dynamics in the packaging machine producer industry as well as in customer markets. For instance, if we look at the producers of packaging machines for the Pharma segment we find that the four world leaders (IMA and Marchesini in Emilia-Romagna and Bosch and Uhlmann in Baden-Württemberg) account for $50 \%$ of world market share. IMA commands $16 \%$ of world market share in the Pharma segment and around $80 \%$ in certain subsets of the Food segment (e.g. tea bags). Today's leading companies in the F\&T and Pharma customer markets require packaging machines producers to be able to operate at a certain production scale, but also to provide customised product solutions and critical post-sale services (e.g. MRO, software upgrading, training etc.). Therefore, reaching a critical mass was extremely important for IMA.

Increasing operational scale, however, requires continuous organisational reconfiguration as the growth of the firm generally leads to rigidities and difficulties in addressing specific technology needs. IMA's technology transition towards the Pharma segment triggered (and was made possible by) three main organisational reconfiguration stages.

First, during the 1980s IMA started preparing and supporting its technology transition towards Pharma by increasing its production capacity in packing, blistering and dosing technologies. IMA acquired a number of companies mainly located within the regional industrial system (CMS, Zanasi, Farmatic, Farmomac, PM System and Cestind Centro Studi Industriali) and in 1990 merged these companies within one unique organisational division. The relationships with its subcontractors mainly located in the ER local production system were not purely horizontal, as traditionally described in the industrial district literature (Becattini, 1979; Brusco, 1982). Although local producers were independent, IMA developed a dense network of subcontracting and commercial relationships and organised their activities as a product system integrator.

Second, between 1995 and 2005, IMA went through a new phase of M\&A, followed by an organisational reconfiguration along customer operating lines and internationalisation. IMA's acquisitions mainly involved companies specialised in specific manufacturing tasks and processes, such as blistering and cartooning (Precision Gears, IN), end-line (BFB), washing and sterilisation (Libra) and capsules 
This is a pre-copyedited, author-produced PDF of an article accepted for publication in Cambridge Journal of Economics following peer review. The version of record is available online at:

http://cje.oxfordjournals.org/content/early/2016/10/07/cje.bew048.abstract

Accepted Version downloaded from SOAS Research Online: http://eprints.soas.ac.uk/23184/

(Kilian, DE and GS Coating). During this period, IMA acquired and integrated a number of complementary resources and capabilities essential for expanding its operations in the Pharma segment and entering specific niches, such as granulators (ICO Oleodinamici) and tube-filling (CO.MA.DI.S.). At the same time internationalisation continued through the acquisitions of complementary capabilities (Swiftpack, U.S.) and industrial collaborations (IMA-Telstar, China).

Thirdly, following on from its dramatic expansion, since mid-2000, IMA has entered another organisational reconfiguration phase. This started with a systematic process of organisational integration as well as changing relationships with the local production system. The first major step in 2007 consisted in the creation of a new company, IMA Libra incorporating the activities of Libra Pharmaceutical Technologies and of IMA Aseptic Processing \& Filling Division. In 2008 the IMA group also assumed a new organisational structure featuring four leading business areas: IMA Flavour Srl (Tea \& Coffee Packaging Solutions), IMA Active Division (Solid Dose Solutions), IMA Life Srl (Aseptic Processing \& Filling Solutions) and IMA Safe Srl (Packaging Solutions). At the end of this organisational reconfiguration, after a number of other acquisitions such as VIMA Impianti (2006), Zanchetta (2007), BOC Edwards Pharmaceutical Systems (2008) and PharmaSiena Service (2009), in 2011, IMA created two holding-divisions: IMA Industries (machines for the packaging of tea, coffee, food and cosmetic products) and IMA Pharma (machines for the processing and packaging of pharmaceutical products) ${ }^{6}$.

Despite major acquisitions and internationalisation, during this last phase the most significant organisational reconfiguration is the one related to IMA's changing relationship with the local suppliers' network. The technology transition in the packaging industry (see section 4.2) had disproportional effects on the different subcontractors and suppliers in the ER regional production system. In response, from the mid-1990s, IMA has implemented a number of strategies targeting critical partners in the regional production system. Overall, IMA supported various processes of technological upgrading by its sub-contractors and suppliers as well as engaging in the de-risking of their production activities with medium-long term guaranteed scheme contracts. This gave a number of companies in the local production system both time and technological support to catch up with the packaging industry's overall structural cycle.

Strategic organisational reconfigurations of the different local production system actors were also supported. First, second-tier suppliers started aggregating in new groups and, sometimes, first-tier suppliers acquired minority shares into said new groups. IMA supported first-tier suppliers in their growth and restructuring processes by conferring capital investments and acquiring minority shares (generally below 35\%). In turn, a number of financial operations and cross-participations in IMA's minority shares (about 3\%) cemented this new organisational configuration at 
This is a pre-copyedited, author-produced PDF of an article accepted for publication in Cambridge Journal of Economics following peer review. The version of record is available online at:

http://cje.oxfordjournals.org/content/early/2016/10/07/cje.bew048.abstract

Accepted Version downloaded from SOAS Research Online: http://eprints.soas.ac.uk/23184/

the system integrator - first-tier suppliers interface. The reorganisation of the ownership structure also led to the introduction of a more integrated corporate governance structure as well as a number of agreements to share operational risks and reduce operational costs via buying consortia.

This organisational reconfiguration had a major impact on the local production system. Traditionally the packaging local production system was an open system. SMEs endowed with advanced instrumentation and production capabilities (including rapid prototyping, hybrid 3D machine tools, injection moulding, etc.) used to work with all the major leading companies (Bigarelli and Russo, 2012). As a result of IMA's third round of organisational reconfiguration and consolidation, some of these SMEs have started establishing more formal and exclusive relationships with IMA. In the long run, of course, this may potentially affect the Marshallian 'atmosphere' in the cluster and make public policy interventions even more important.

\subsection{Industrial policy alignment and the role of public technology intermediaries in Emilia-Romagna.}

In those industries affected by profound technological and organisational transformations, the effectiveness of industrial policies strongly depends on their alignment with the industry's structural cycles. This is because the specific needs of productive organisations change along these structural cycles. Therefore, matching these needs (as well as steering certain transitions) requires properly aligned public policies, including time-specific technology support, production services and training.

Since 1970s ER's industrial policies went through three major phases and developed along two main axes, that is, sectoral and technology policies and industrial training policies. While the former witnessed significant adjustments in each of these three major industrial policy phases, industrial training policies remained substantially the same during the first two phases (1974 - 1985 and 1985 - 2003) and underwent an important reform only during the third and final phase (2003 - ). The packaging sector and technologies have been among the main industrial policy targets of the ER regional government and received various forms of direct and indirect support (Fig. 6). 
This is a pre-copyedited, author-produced PDF of an article accepted for publication in Cambridge Journal of Economics following peer review. The version of record is available online at:

http://cje.oxfordjournals.org/content/early/2016/10/07/cje.bew048.abstract

Accepted Version downloaded from SOAS Research Online: http://eprints.soas.ac.uk/23184/

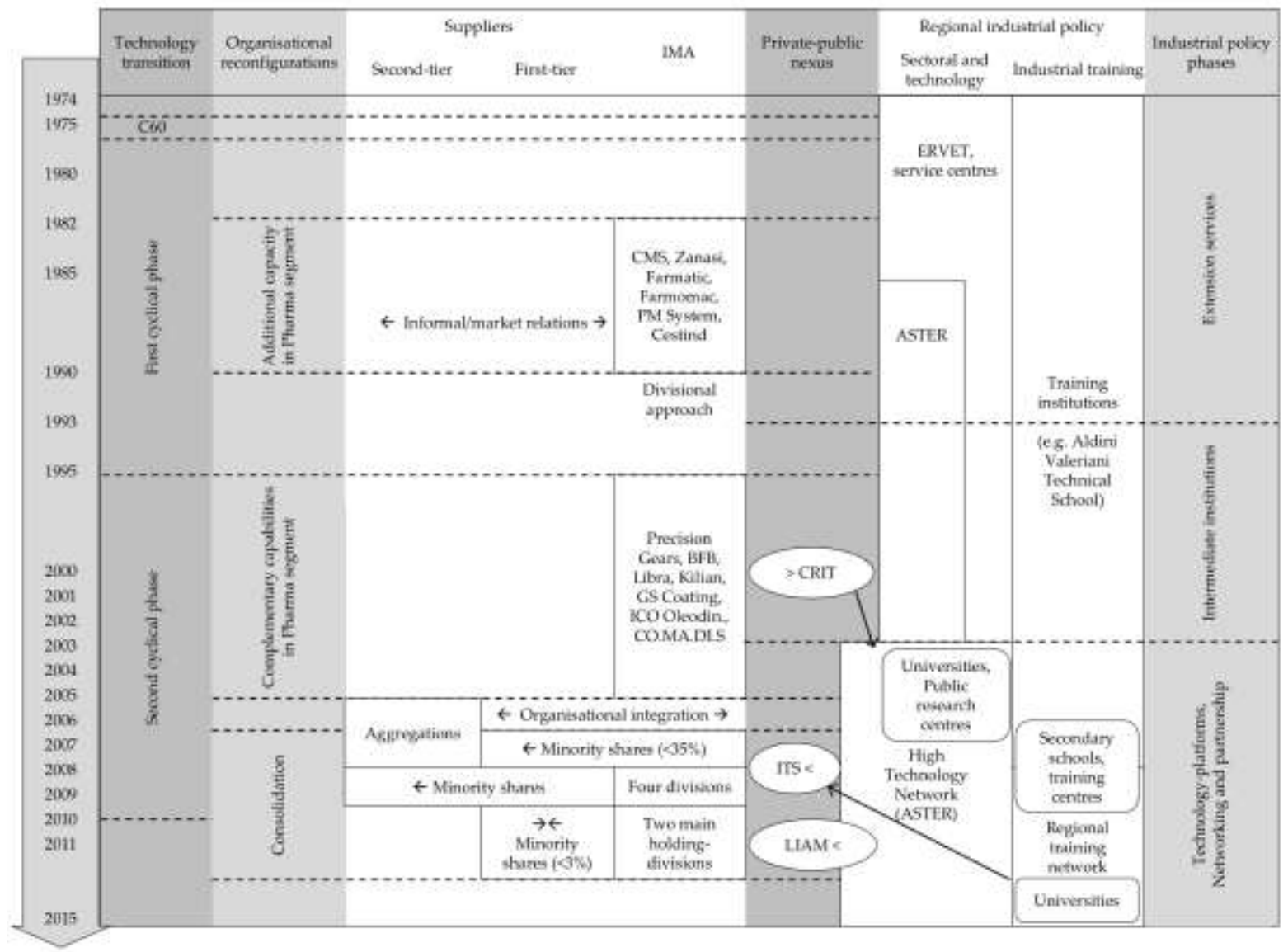

Fig. 6. The private-public nexus in the Emilian Packaging Valley: Technology transition and organisational reconfigurations in IMA and their alignment to the regional industrial policies. Source: Authors.

The sectoral and technology policies started in 1974 with the establishment of ERVET (ER Governmental Agency for the Economic Valorisation of the Territory). This coordination agency launched and organised a regional network of sector-focused research centres targeting SMEs (Regional Law no. 44/1973). ERVET's service centres provided various types of manufacturing extension services, including technology diffusion, technical assistance and consultancy, market analysis and scouting, fair and exhibition services, specialised and continuous training. These activities were aimed at supporting SMEs in capabilities development, technology absorption, scaling up production capacity alongside increasing quality, product certification and standards. These services were all extremely important for companies like IMA whose production relied extensively on local SMEs. Without reaching a certain threshold of production quality in the provision of components, SMEs in the packaging industry would have remained de-linked from the technology-cycles in the food packaging segment. 
This is a pre-copyedited, author-produced PDF of an article accepted for publication in Cambridge Journal of Economics following peer review. The version of record is available online at:

http://cje.oxfordjournals.org/content/early/2016/10/07/cje.bew048.abstract

Accepted Version downloaded from SOAS Research Online: http://eprints.soas.ac.uk/23184/

During the 1980s the ERVET network was further extended. However the regional government started realising that SMEs (and indirectly the new emerging system integrators such as IMA) increasingly faced new types of production and technology challenges. From the mid-80s key industrial sectors (including the packaging one) started integrating mechanics and electronics within their technology platforms as well as increasing their operational scale and markets. In response to these industrial transformations, the regional government launched a new Agency for Technological Development called ASTER in 1985. ASTER represented an important shift in two main respects. First, regional industrial policies became more technology focused and the support services started targeting the most innovative and dynamic SMEs. Second, the emergence of a local 'network of innovating SMEs' providing smart technology solutions at the level of production technologies, materials and product components became one of the key competitive assets for the entire region and its emerging leading companies.

The creation of ASTER was followed by a gradual reform of the overall regional technology infrastructure culminating in the Regional Law no. 25/1993. The many research and service centres run by ERVET (including ASTER) were encouraged to take a more entrepreneurial approach, in part by targeting European Structural Funds Projects and engaging more proactively with business organisations. These institutions became the main 'intermediaries' between the regional government and the business organisations (Bellini, 1996).

During these two initial phases the regional industrial system benefitted from the presence of strong engineering departments in the region's universities and its many technical schools, including the Aldini Valeriani Technical School in Bologna. However, during the second phase, the signs of a misalignment between the educational system and the new industrial needs started emerging. Business organisations had to complement formal education with long-term in-firm training programmes. In the case of IMA, these training programmes could last as long as 6-8 months. The re-alignment of the education system to the industrial transformations of the regional industrial system had to wait until the second half of 2000.

The third and final industrial policy phase started in 2003 with the PRRIITT (Regional Program for Industrial Research, Innovation and Technology Transfer). The PRRIITT was the government most systematic attempt to re-align its PTIs to the industrial transformations characterising the manufacturing landscape from the late 1990s. As shown in section 4.2, this was the beginning of the major technology transition and organisational reconfiguration in the packaging industry and the major shift for IMA towards the Pharma segment. 
This is a pre-copyedited, author-produced PDF of an article accepted for publication in Cambridge Journal of Economics following peer review. The version of record is available online at:

http://cje.oxfordjournals.org/content/early/2016/10/07/cje.bew048.abstract

Accepted Version downloaded from SOAS Research Online: http://eprints.soas.ac.uk/23184/

This policy re-alignment consisted of a major technology upgrading of the regional system of PTIs and the adoption of a more flexible and cooperative approach open to various public-private partnerships (PPPs). First, the PRRIITT Measure 4 instituted a regional network of applied research laboratories and technology transfer innovation centres, named the High Technology Network (HTN). The HTN marked a transition from a sector-specific industrial policy to a technology policy selecting six specific technology platforms (mechanics and materials, ICT, agro-industrial, construction, energy and environment and life sciences) based on an appreciation of the developing structural trajectory of the ER local production system. ASTER was restructured and a number of regional universities and research institutions (CNR and ENEA) located in Emilia-Romagna were involved (Regional Law no. 7/2002).

Over the years, the access to the HTN was facilitated by the creation of specific tools for increasing the interaction between business organisations and the PTIs as well as aligning their technology efforts. In particular, the establishment of a regional web platform called the 'Catalogue of Competencies' played an important role in mapping existing technology offerings and production services in the region. The technology offerings and services for the mechanics, materials and ICT platforms include a wide range of critical activities for the packaging industries. These include embedded systems, automation and control, robotics, high performance and cloud computing, internet of things, software engineering, interoperability, protocols and standards, mechatronics applications, vibration and harshness analysis. The technology offerings and services for the mechanics, materials and ICT platforms include a wide range of critical activities for the packaging industries. These mainly are embedded systems, automation and control, robotics, high performance and cloud computing, internet of things, software engineering, interoperability, protocols and standards, mechatronics applications, vibration and harshness analysis. All of these activities were selected specifically because they were crucial in the technological transformation process taking place at that point in the structural cycle. For the Pharma segment, the life sciences platform has also acquired increasing relevance. Since its constitution, IMA and a number of its suppliers have established collaborations with the local universities, innovation centres and laboratories involved in the HTN.

The regional government also managed to re-align the interaction between private research institutions as well as between business organisations and the HTN. In the packaging industry, at the apex of the technology transition from the mechanics to the mechatronics platform, twenty six Emilian packaging companies, including IMA, created a private company called CRIT Research. Before the PRRIITT, CRIT was the main technology intermediary within the packaging industry and between the EPV and international research centres. Since 2003, the CRIT was integrated within the public PTI system and new initiative of this type started receiving public support. 
This is a pre-copyedited, author-produced PDF of an article accepted for publication in Cambridge Journal of Economics following peer review. The version of record is available online at:

http://cje.oxfordjournals.org/content/early/2016/10/07/cje.bew048.abstract

Accepted Version downloaded from SOAS Research Online: http://eprints.soas.ac.uk/23184/

Thanks to regional funding opportunities, in 2011 five among the companies who founded CRIT Research (IMA, SITMA, SACMI, SELCOM and Tetra Pak Packaging Solutions) created a new intermediate institution called LIAM (Industrial Laboratory for Packaging Automated Machines). This research centre offers technology services such as virtual prototyping, solutions for predictive diagnostic, software architecture machine-independent and platform-independent, access to instrumentation for testing and benchmarking different technology solutions and platforms adopted by international competitors.

During this third and final phase of industrial policy, in 2008 the ER government finally addressed the increasing misalignments and gaps in the education system. Specifically, the regional reform introduced an articulated vocational and industrial training programme spanning from the secondary school to the tertiary education level. At the centre of this system were the ITSs (Advanced Technical Institutes) which were totally transformed. They were made into Foundations with the participation of companies, schools, training centres, universities, and other local institutions. They offer alternative training programmes aligned to the specific industrial needs of local business organisations. Leading companies in the region have played a key role in the establishments of these foundations. For example, IMA is one of the key stakeholders of a new institute called ITSMAKER (Istituto Tecnico Superiore Meccanica Meccatronica Motoristica e Packaging) focused on mechanics, mechatronics, motors and packaging technologies.

In sum, the interaction between the regional government and the business organisations have been changing since mid-1970s. During the first industrial policy phase the public policy support to the packaging industry was mainly indirect, sector focused and SMEs targeted. During the second and third phases the ER regional government undertook important efforts towards a better alignment of its policies and the adoption of a more flexible approach. This opened a new space between the public and business organisations, including initiatives by leading companies as well as SMEs. The resulting private-public nexus appears today as a complex and dense system of interlocking relationships including multiple technological and organisational dimensions.

\section{Policy implications and concluding remarks}

The interaction between business organisations and public policy continuously changes over time as a result of industrial transformations. Therefore, the privatepublic nexus is constituted by multiple evolving interfaces and relationships among multiple actors. This paper argues that in order to address the multi-dimensional and multi-level process of industrial transformation triggering these dynamic interactions, three sets of heterodox theories (structural economic dynamics, 
This is a pre-copyedited, author-produced PDF of an article accepted for publication in Cambridge Journal of Economics following peer review. The version of record is available online at:

http://cje.oxfordjournals.org/content/early/2016/10/07/cje.bew048.abstract

Accepted Version downloaded from SOAS Research Online: http://eprints.soas.ac.uk/23184/

resource-capability theories of the firm and evolutionary-life cycle approaches) should be integrated towards a new structural-resource-capability synthesis.

These theories present strong complementarities and their integration allow for the theorisation of the intrinsic link between structural dynamics (at the macro-meso level) and changes in technology and business organisations (at the micro-meso level). Building on this synthesis, this paper proposed the concept of the structural cycle as a new heuristic to disentangle changes in the relationships between business organisations and various public actors. We defined structural cycles as transformational phases of technology transition and organisational reconfiguration that business organisations experience when they shift towards the opportunities found in higher value product segments.

This analytical heuristic does not simply point to the main dynamics characterising industrial transformations, it also suggests the importance of aligning selective policy interventions to changes in technology platforms and organisations. So, to examine these alignments we analysed, both theoretically and empirically, the specific cyclical patterns of technology transition and organisational reconfiguration underpinning the industrial transformation in the packaging industry in the context of the ER local production system. The industrial policy responsiveness of the regional government and its intermediaries was assessed by looking at the ways in which public policies and institutions were aligned to the specific structural cycle experienced by the packaging industry and, in particular, its leading company IMA.

The empirical analysis elucidated a number of hypotheses and stylisations emerging from the theoretical framework.

First, the packaging industry underwent a major technology transition at the level of its technology platform. This transition (driven by the integration of electronics, information and communication technologies with more traditional mechanical technologies) allowed companies such as IMA to shift towards higher value product segments such as Pharma.

Second, the combined effect of technology transition and new product-segments opportunities triggered organisational reconfigurations in the major system integrator IMA, and industrial restructuring of their local production system. IMA's organisational response to the technology transition consisted of a process of 'verticalisation' of critical production tasks and the establishment of new strategic partnerships with local producers as well as public intermediate institutions. These are the two complementary dynamics we identified as a structural cycle in the packaging industry.

Third, the ER regional government managed to align its industrial policy and PTIs with the structural cycle characterising the local packaging-machine production 
This is a pre-copyedited, author-produced PDF of an article accepted for publication in Cambridge Journal of Economics following peer review. The version of record is available online at:

http://cje.oxfordjournals.org/content/early/2016/10/07/cje.bew048.abstract

Accepted Version downloaded from SOAS Research Online: http://eprints.soas.ac.uk/23184/

system. In the case of the EPV, this was made possible by taking into consideration the evolving needs of the different business organisations at different stages of the structural cycle and combining a mix of both direct and indirect interventions.

Our case study analysis points to a number of critical policy issues for sustainable value creation dynamics in local production systems. First, governments may be more or less responsive to industries' structural cycles and public policies more or less targeted on business organisations' specific needs. Indeed, in different phases the same government can show different degrees of responsiveness and public policies can be more or less targeted. While ex-ante both governments and business organisations might not know how to best calibrate their evolving interactions, the creation of a private-public nexus is a critical step for discovering new opportunities and developing PPPs. The public-private nexus is the space for composing private and public interests, intermediating resources and productive opportunities and aligning the technology, organisational and industrial policy mechanisms whereby manufacturing system transform and create value.

Certainly, other approaches would be helpful in extending the 'analytic generalisations' provided. A first step in this direction could be obtaining cross-case conclusions through a multiple-case study comparing local production systems and context-specific policy actions. Additionally, history-friendly modelling, which "aim[s] to capture, in stylized form, qualitative and 'appreciative' theories about the mechanisms and factors affecting industry evolution, technological advance and institutional change" (Malerba, 1999:3) could be instrumental in conceptualising the constitutive dynamics behind the concept of structural cycle and, consequently (the hypothesis of industrial policy) facilitating structural cycle alignment. Last, an extensive collection of data across cases would allow the measurement of what our in-depth analysis has highlighted and the literature has not fully disentangled nor studied yet: the intensity of industrial relatedness which make possible major shifts across product segments; how new technological trajectories at a platform level can absorb (or not) evolutionary patterns at a sectoral level; the readiness to change of a firm and whole production system; which private-public interfaces can better channel these dynamics and favour the actual alignment of public policies to structural cycles.

\section{Notes}

${ }^{1}$ According to the Census of Industry and Services conducted by the Italian Institute of Statistics (Istat), in 2011 Emilia-Romagna had 512 companies operating in the manufacture of automatic machines for dispensing, dosing and packaging (NACE Rev. 2 28.29.3) with a total employment reaching $14,600(3.22 \%$ of the total manufacturing employment in the region). Roughly one half of these companies are 
This is a pre-copyedited, author-produced PDF of an article accepted for publication in Cambridge Journal of Economics following peer review. The version of record is available online at:

http://cje.oxfordjournals.org/content/early/2016/10/07/cje.bew048.abstract

Accepted Version downloaded from SOAS Research Online: http://eprints.soas.ac.uk/23184/

in the Bologna area (249 firms for 7,414 employees, equal to $7.23 \%$ of the total manufacturing employment in the region).

2 The sectors studied are the NACE Rev. 1 subsections 15 (Foods, beverages) and 16 (Tobacco products) for F\&T segment, and NACE Rev. 1 groups 24.4 (Pharmaceuticals), 24.5 (Soaps, detergents, toilet preparations) and 33.1 (Medical equipment) for Pharma. Of course each selection criterion suffers limitations. In this case the definition of segment-related technologies is quite restrictive and the count of patents tracked is probably underestimated. General or transversal packaging technologies are also applied within segments and segment subsets and include distinctive technologies that are not exclusive, but rather complementary to other packaging technologies.

${ }^{3}$ EIC technologies are defined here as fractions of patents mentioning IPC subclasses related to NACE Rev. 130 (Office machinery and computers), 32.1 (Electronic components), 32.2 (Signal transmission, telecommunications), 33.2 (Measuring instruments) and 33.3 (Industrial process control equipment) in the NACE Rev. 1.

${ }^{4}$ The comparison of different-size variables imposes the exclusion of some data dimensions and z-scores transformation. Despite the fact that this statistical solution removes all the intensity-related issues previously discussed, it allows us to stress precisely the connections between different technological dynamics.

${ }^{5}$ Several solutions have been tested to best represent the role of control system platforms across segments. The one chosen here is the comparison between adjusted shares or weights of control systems technologies in the total. Accordingly, we count control systems fractions of patents and calculate the ratio over a total count. Shares are adjusted excluding factions of segment-specific technologies from totals in order to avoid that the relevance of control system platform would be biased by selection criteria adopted in choosing segment subgroups.

${ }^{6}$ Interestingly, since 2010 IMA's M\&As have focused on the F\&T segment, especially on specific packaging niches with GIMA (Bologna, 2010), the "Diary \& Convenience Food" and "Chocolate \& Confectionery" divisions of Sympack Corazza (Bologna, 2011), CMH (joint venture with SACMI, Bologna, 2011), Ilapack $(\mathrm{CH}, 2013)$ and Oystar (DE, 2014). In line with the technology cycle analysis, IMA might be entering in a new technology cycle driven by higher value product segments around F\&T.

\section{Acknowledgments}

The authors thank all the firms, institutions and stakeholders involved in the study for their valuable inputs, including IMA Spa (in particular Massimo Marchesini) Logimatic Srl, IEMA Srl, the Regional Government of Emilia-Romagna (in particular 
This is a pre-copyedited, author-produced PDF of an article accepted for publication in Cambridge Journal of Economics following peer review. The version of record is available online at:

http://cje.oxfordjournals.org/content/early/2016/10/07/cje.bew048.abstract

Accepted Version downloaded from SOAS Research Online: http://eprints.soas.ac.uk/23184/

Patrizio Bianchi and Silvano Bertini), CRIT and LIAM of the Emilia-Romagna High Technology Network. We also acknowledge helpful comments from Mike Best, Bill Lazonick and Hassan Akram. Marco Bertinelli provided valuable technical inputs. We are finally thankful to two anonymous referees for their valuable comments to the manuscript and their constructive suggestions. The usual caveat applies.

\section{Bibliography}

Aftalion, A. 1927. The theory of economic cycles based on the capitalistic technique of production, The Review of Economics and Statistics, vol. 9, no. 4, 165-70

Amin, A. 1999. The Emilian model: Institutional challenges. European Planning Studies, vol. 7, no. 4, 389-405

Andreoni, A. 2014. Structural Learning: embedding discoveries and the dynamics of production, Structural Change and Economic Dynamics, vol. 29, 58-74

Andreoni, A. 2016. Varieties of Industrial Policy: Models, Packages and Transformation Cycles, in Noman, A. and Stiglitz, J. (eds.), Efficiency, Finance and Varieties of Industrial Policy, New York, Columbia University Press

Andreoni, A. and Scazzieri, R. 2013. Triggers of Change: structural trajectories and production dynamics, Cambridge Journal of Economics, vol. 38, no. 6, 1391-1408

Becattini, G. 1979. Dal 'settore' industriale al 'distretto' industriale. Alcune considerazioni sull'unità di indagine dell'economia industriale, Rivista di economia e politica industriale, vol. 1979, no. 1, 7-21

Bellini, N. 1996. Regional economic policies and the non-linearity of history, European Planning Studies, vol. 4, no. 1, 63-74

Best, M. 1990. The New Competition: Institutions of Industrial Restructuring, Cambridge, Mass., Cambridge University Press.

Best, M. 1999. Regional Growth Dynamics: A Capabilities Perspective, Contributions to Political Economy, vol. 18, no. 1, 105-19

Bianchi, P. and Bellini, N. 1991. Public policies for local network of innovators, Research Policy, vol. 20, no. 5, 487-97

Bianchi, P. and Labory, S. 2011. Industrial policy after the crisis: the case of the Emilia-Romagna region in Italy, Policy Studies, vol. 32, no. 4, 429-45

Bigarelli, D. and Russo, M. 2012. 'Gli effetti della crisi internazionale sulla subfornitura meccanica in Emilia-Romagna', DEMB working paper, no. 3 
This is a pre-copyedited, author-produced PDF of an article accepted for publication in Cambridge Journal of Economics following peer review. The version of record is available online at:

http://cje.oxfordjournals.org/content/early/2016/10/07/cje.bew048.abstract

Accepted Version downloaded from SOAS Research Online: http://eprints.soas.ac.uk/23184/

Breschi, S., Lissoni, F. and Malerba F. 2003. Knowledge-relatedness in firm technological diversification, Research Policy, vol. 32, no. 1, 69-87

Brusco, S. 1982. The Emilian model: productive decentralisation and social integration, Cambridge Journal of Economics, vol. 6, no. 2, 167-84

Chang, H.-J. 1994. The Political Economy of Industrial Policy, London and Basingstoke: Macmillan

Chang, H.-J. and Andreoni, A. 2016. 'Industrial Policy in a Changing World: Basic Principles, Neglected Issues and New Challenges', 40 Years of the Cambridge Journal of Economics Conference, 12-13 July, Cambridge.

Coase, R.H. 1937. The nature of the firm, Economica, vol. 4, no. 16, 386-405

Demsetz, H. 1988. The Theory of the Firm Revisited, Journal of Law, Economics, \& Organization, vol. 4, no. 1, 141-61

Dosi, G. 1982. Technological paradigms and technological trajectories: A suggested interpretation of the determinants and directions of technical change, Research Policy, vol. 11, no. 3, 147-62

Dosi, G., Nelson, R.R. and Winter, S.G. 2000. (eds.), The Nature and Dynamics of Organizational Capabilities, Oxford: Oxford University Press

Fortis, M. and Carminati, M. 2014. The Automatic Packaging Machinery Sector in Italy and Germany, Heidelberg, Springer

Goodwin, R.M. 1987. Macrodynamics, in Goodwin, R.M. and Punzo, L.F. (eds.), The Dynamics of a Capitalist Economy. A Multi-Sectoral Approach, Cambridge, Polity Press, 3-160

Griliches, Z. 1990. Patent Statistics as Economics Indicators: A Survey, Journal of Economic Literature, vol. 28, no. 4, 1661-1707

Hobday, M. 2000. The project-based organisation: an ideal form for managing complex products and systems?, Research Policy, vol. 29, no. 7-8, 871-93

Kaldor, N. 1966. Causes of the Slow Rate of Economic Growth of the United Kingdom, Cambridge, Cambridge University Press

Kaldor, N. 1967. Strategic Factors in Economic Development, Ithaca, New York State School of Industrial and Labor Relations, Cornell University

Kaldor, N. 1972. The irrelevance of equilibrium economics, The Economic Journal, vol. 82 , no. $328,1237-55$

Kaldor, N. 1985. Economics without Equilibrium, New York, ME Sharpe 
This is a pre-copyedited, author-produced PDF of an article accepted for publication in Cambridge Journal of Economics following peer review. The version of record is available online at:

http://cje.oxfordjournals.org/content/early/2016/10/07/cje.bew048.abstract

Accepted Version downloaded from SOAS Research Online: http://eprints.soas.ac.uk/23184/

Keller, W. 2004. International Technology Diffusion, Journal of Economic Literature, vol. 42 , no. $3,752-82$

Klepper, S. 1997. Industry Life Cycles, Industrial and Corporate Change, vol. 6, no. 1, $145-82$

Kuznets, S. 1971. Economic Growth of Nations: Total Output and Production Structure, Cambridge, MA, Harvard University Press

Landesmann, M. and Scazzieri, R. 1990. (eds.), The Economic Theory of Structure and Change, Cambridge, Cambridge University Press.

Landesmann, M. and Scazzieri, R. 1996. Coordination of production processes, subsystem dynamics and structural change, in Landesmann, M. and Scazzieri, R. (eds.), Production and Economic Dynamics, Cambridge, UK, Cambridge University Press, 304-43

Lazonick, W. 2010. The Chandlerian Corporation and the Theory of Innovative Enterprise, Industrial and Corporate Change, vol. 19, no. 2, 317-49

Loasby, B.J. 1999. Knowledge, institutions, and evolution in economics, London, Routledge

Mahoney, J.T., McGahan, A.M. and Pitelis, C.N. 2009. The Interdependence of Private and Public Interests, Organization Science, vol. 20, no. 6, 1034-52

Malerba, F. 1999. 'History-friendly' models of industry evolution: the computer industry, Industrial and Corporate Change, vol. 8, no. 1, 3-40

Marshall, A. 1920. Industry and trade, London, Macmillan

Mazzucato, M. 2013. The Entrepreneurial State: Debunking Public Vs. Private Sector Myths, London, Anthem Press

Menzel, M.-P. and Fornahl, D. 2010. Cluster Life Cycles - dimensions and rationales of cluster evolution, Industrial and Corporate Change, vol. 19, no. 1, 205-38

Neffke, F., Henning, M., Boschma, R., Lundquist, K.-J. and Olanders, L.-O. 2011. The Dynamics of Agglomeration Externalities along the Life Cycle of Industries, Regional Studies, vol. 45, no. 1, 49-65

Nelson, R.R. and Winter, S.G. 1982. An Evolutionary Theory of Economic Change, Cambridge, MA, Belknap Press

Nelson, R.R. and Winter, S.G. 2002. Evolutionary theorizing in economics, Journal of Economic Perspectives, vol. 16, no. 2, 23-46 
This is a pre-copyedited, author-produced PDF of an article accepted for publication in Cambridge Journal of Economics following peer review. The version of record is available online at:

http://cje.oxfordjournals.org/content/early/2016/10/07/cje.bew048.abstract

Accepted Version downloaded from SOAS Research Online: http://eprints.soas.ac.uk/23184/

O'Sullivan, E., Andreoni, A., Lopez-Gomez, G. and Gregory, M. 2013. What is New in the New Industrial Policy? A Manufacturing System Perspective, Oxford Review of Economic Policy, vol. 29, no. 2, 432-62

OECD. 2009. Patent Statistic Manual, Paris, OECD

Pasinetti, L.L. 2007. Keynes and the Cambridge Keynesians, Cambridge, Cambridge University Press

Pasinetti, L.L. 2012. 'Growth and Structural Change' and 'The Significance of Structural Economic Dynamics', in Arena, R. and Porta P.L. (eds.), Structural Dynamics and Economic Growth, Cambridge, Cambridge University Press

Penrose, E.T. 1959. The Theory of the Growth of the Firm, Oxford, Oxford University Press

Pitelis, C.N. 2002. (ed.) The Growth of the Firm: The Legacy of Edith Penrose, Oxford, Oxford University Press, 127-46

Pitelis, C.N. 2012. Clusters, entrepreneurial ecosystem co-creation and appropriability: A conceptual framework, Industrial and Corporate Change, vol. 21, no. $6,1359-88$

Pitelis, C.N. and Teece, D. 2009. The new nature and essence of the firm, European Management Review, vol. 6, no. 1, 5-15

Richardson, G.B. 1960. Information and Investment. A study in the working of the competitive economy, Oxford, Clarendon Press

Richardson, G.B. 1972. The Organisation of Industry, Economic Journal, vol. 82, no. 327, 883-96

Robinson, J. 1956. The Accumulation of Capital, London, Macmillan

Robinson, J. 1977. What are the questions?, Journal of Economic Literature, vol. 15, no. 4, 1318-39

Rosenberg, N. 1976. Perspectives on Technology, Cambridge, Cambridge University Press

Rosenberg, N. 1994. Exploring the black box: technology, economics, and history, Cambridge, Cambridge University Press

Schmoch, U., Laville, F., Patel, P. and Frietsch, R. 2003. 'Linking Technology Areas to Industrial Sectors', Final Report to the European Commission, DG Research

Schumpeter, J.A. 1911. The theory of economic development: An Inquiry into Profits, Capital, Credit, Interest, and the Business Cycle, Transaction Publishers 
This is a pre-copyedited, author-produced PDF of an article accepted for publication in Cambridge Journal of Economics following peer review. The version of record is available online at:

http://cje.oxfordjournals.org/content/early/2016/10/07/cje.bew048.abstract

Accepted Version downloaded from SOAS Research Online: http://eprints.soas.ac.uk/23184/

Segerstrom, P., Anant, T.C.A. and Dinopoulos, E. 1990. A Schumpeterian Model of the Product Life Cycle, American Economic Review, vol. 80, no. 5, 1077-91

Simon, H.A. 1962. The Architecture of Complexity, Proceeding American Philosophical Society, vol. 106, no. 6, 467-82

Simon, H.A. 1983. Reason in Human Affairs, Stanford, CA, Stanford University Press

Simon, H.A. 1991. Bounded Rationality and Organizational Learning, Organization Science, vol. 2, no. 1, 125-34

Tassey, G. 2007. The Technology Imperative, Cheltenham, Edward Elgar

Teece, D. 2007. Explicating dynamic capabilities: the nature and microfoundations of (sustainable) enterprise performance, Strategic Management Journal, vol. 28, no. 13, 1319-50 Young, A.A. 1928. Increasing Returns and Economic Progress, The Economic Journal, vol. 38, no. 152, 527-42

Wilkinson, F. 1983. Productive systems, Cambridge Journal of Economics, vol. 7, 413429 